\title{
Effect of edible oils on different stages of pulse beetle (Callosobruchus chinensis L.) on chickpea grains
}

\section{SN Bushra \& TB Devi}

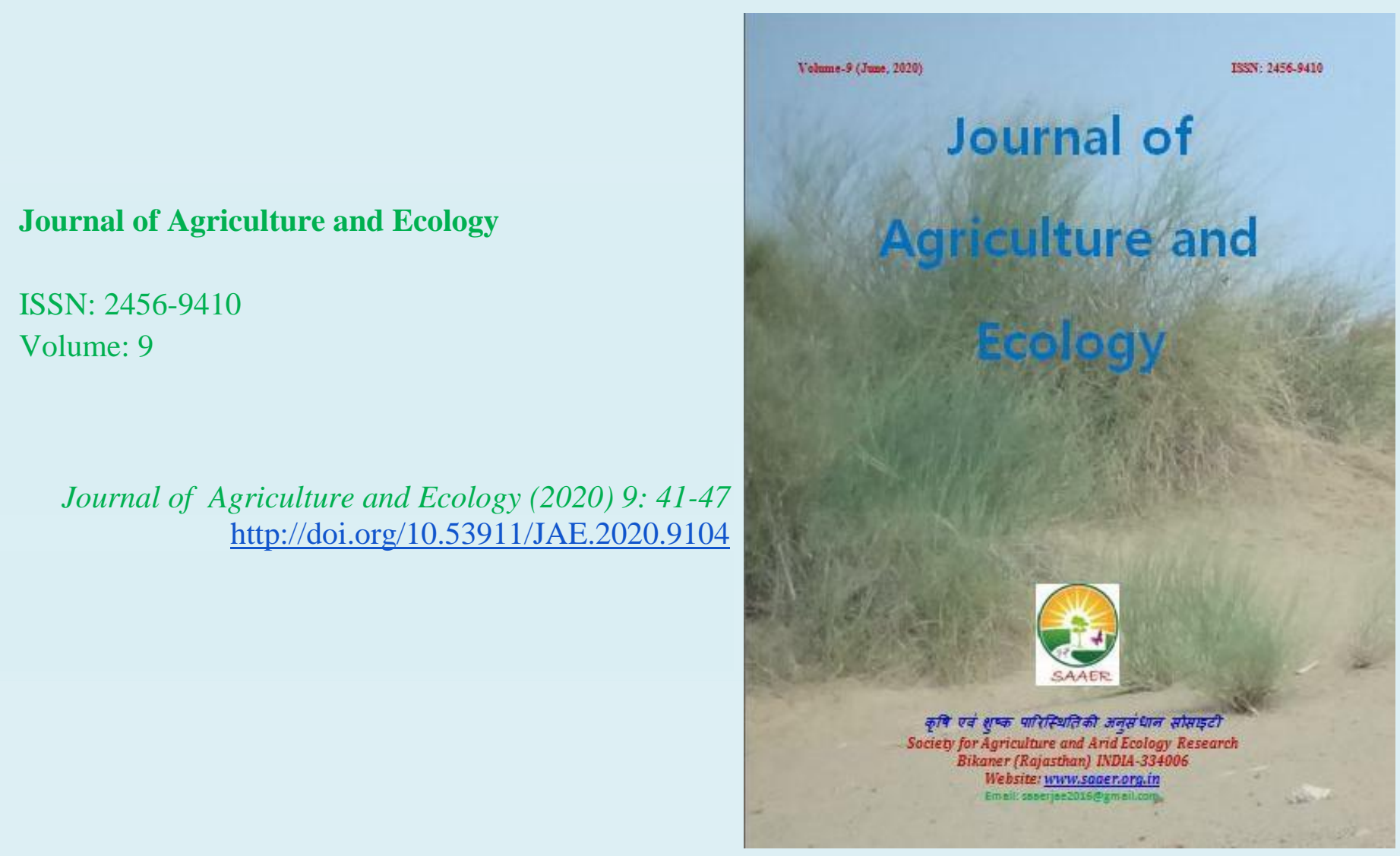


Effect of edible oils on different stages of pulse beetle (Callosobruchus chinensis $\mathrm{L}_{\text {.) }}$ on chickpea grains

SN Bushra $\square \&$ TB Devi

Department of Entomology, College of Agriculture

Central Agricultural University, Imphal - 795004

Permanent address: Asmara Eritrea, East Africa

\Corresponding author: SN Bushra, saidnur265@gmail.com

\section{Article Info}

Article history

Received: 29 May 2020

Accepted: 12 June 2020

Available online: 30 June 2020

Key Words: Pulse beetle, Callosobruchus chinensis, oviposition, protectants, edible oils.

\section{Abstract}

Among the five edible oils viz. olive oil (Olea europaea L), coconut oil (Cocos nucifera L.), groundnut oil (Arachis hypogaea L.), mustard oil (Brassica spp L.) and sesame oil (Sesamum indicum L.) @ 3, 6 and $9 \mathrm{ml} \mathrm{kg}$ ${ }^{1}$ grains were evaluated as protectants of $C$. arietinum against oviposition, adult mortality and adult emergence. Pulse beetles favoured untreated rather than treated grains. Similarly, irrespective of these oils, at the rate of $3 \mathrm{ml}$ $\mathrm{kg}^{-1}$ was less effective in inhibiting the oviposition, adult mortality and adult emergence inhibition than 6 and $9 \mathrm{ml} \mathrm{kg}^{-1}$. Among the oils, coconut oil at 9 $\mathrm{ml} \mathrm{kg}^{-1}$ grains was found to be most effective in inhibiting the oviposition (26.43 eggs), adult mortality (44.52\%) and adult emergence inhibition $(96.34 \%)$ and did not affect germination of chickpea grains till four months. Sesame oil also provided excellent results giving in the same parameters as 26.62 eggs, 40.95 and 96.08.percent, respectively. Oils of groundnut and olive were least effective in performing the above parameter in the process of the investigation.

Copyright (C2020 Bushra \& Devi, This is an open access article published under the terms of the Creative Commons Attribution License, which permits unrestricted use, distribution, and reproduction in any medium, provided the original work is properly cited.

Preferred citation: Bushra SN \& Devi TB. 2020. Effect of edible oils on different stages of pulse beetle (Callosobruchus chinensis L.) on chickpea grains. Journal of Agriculture and Ecology, 9: 41-47; http://doi.org/10.53911/JAE.2020.9104.

\section{Introduction}

Among the pulses, chickpea (Cicer arietinum L.) is the third most important cool season food legume in the world after common bean (Phaseolus vulgaris L.) and field pea (Pisum sativum L.) (Ahmad et al. 2005). Among the pulses grown in India, gram occupies a predominant position and is considered as a king of pulses (Vishwas et al.
2017). Cultivated chickpeas are mainly divided into two main types of chickpea-based on plant characteristics, seed size, shape, and coloration as desi and kabuli. Desi has small, darker seeds and a rough coat grown mainly in India, Ethiopia, Mexico, and Iran. "Desi" means 'country' or 'local'; its other names include Bengal gram or Kala chana which means black chickpea or Chola boot. Kabuli is 
lightly-colored, larger, and with a smoother coat and is mainly grown in the Mediterranean, South America, and Southeast Asia. (FOA 2016).

Amongst the most important insect damaging pulses in field and storage, the pulse beetle, $C$. chinensis, is considered to be the most important and economic pest. It is one of the most destructive pests of chickpea and assumes greater importance as they damage the final product in the field as well as in the store. It is cosmopolitan and a serious pest of mung, peas, cowpeas, and lentil and has also been reported attacking cottonseed, sorghum, and maize (Ahmed et al. 2003, Choudhary et al. 2017a\&b). The eco-toxicological, environmental, and social consequences of the widespread use of chemical insecticides in agriculture have led researchers to find viable alternatives that are more environmentally friendly than synthetic chemicals. In this context, the use of edible oils (EOs) is a promising alternative because of their worldwide availability, relative costeffectiveness, and required in few amounts.

Materials and Methods

Collection of chickpea grain and preparation of treatment materials

Farmers and consumers preferred the desi type of chickpea grain (Cicer arietinum L.) that was purchased from the local market of Imphal city to be used for the study. All samples were brought to $12 \%$ moisture content before use in the laboratory at room temperature. The grain was thoroughly cleaned, sun-dried, cooled, and stored at $12 \%$ moisture content. The grains were kept in an airtight plastic container $(25 \mathrm{~cm}$ height $\mathrm{x} 15 \mathrm{~cm}$ diameter) and preserved at room temperature for further study.

Treatment units: Five edible oils representing different plant families were purchased from market of Imphal city, Manipur which was done a week before application of the treatments. Among the five edible oils viz., olive oil (Olea europaea L), coconut oil (Cocos nucifera L.), groundnut oil (Arachis hypogaea L.), mustard oil (Brassica spp L.) and sesame oil (Sesamum indicum L.) @ 3, 6 and $9 \mathrm{ml} \mathrm{kg}^{-1}$ grains were evaluated as protectants of $C$. arietinum against oviposition, adult mortality, adult emergence of $C$. chinensis over a storage period of four months.

Culture of $\boldsymbol{C}$. chinensis: To obtain newly emerged pulse beetles of the same generation, fifty pairs of one-day-old beetles from the initial culture were released into cylindrical jars measuring $(25 \times 15 \times 10 \mathrm{~cm})$ containing 1000 gm grain.

Male and female pulse beetles were sorted out according to their size, shape, and other morphological characters of the body. Once pulse beetle started to emerge, they were introduced and allowed for oviposition in a large plastic container having 1000gram of chickpea grains. Afterward newly emerged adults were shifted to other containers; consequently rearing procedure was repeated on different batches to ensure a continuous supply of the test insect.

Details of experiment: Hundred grams of undamaged chickpea grains were placed into a capacity $250 \mathrm{~g}$ plastic container $(8.5 \mathrm{~cm}$ height $\times 7.5 \mathrm{~cm}$ diameter). Edible oil treatments at a rate of $0.3,0.6$, and $0.9 \mathrm{ml}$ were thoroughly mixed with $100 \mathrm{~g}$ of grains. The quantity of oil 
for all the treatments was measured with the help of a micro-pipette and discharged on the grains with separate micro-pipette for each oil treatments and mixed manually. Oils were not being applied in the control treatment. Ten pairs of one-day-old adult $C$. chinensis were released in each plastic container including the control and the containers were closed with perforated lids. The pulse beetle was handled carefully with the help of a pair of forceps having blunt ends, camel hairbrush, and aspirator also used invariably for transferring insects into plastic jars treated with oils.

\section{Observation recorded}

Ovipositor inhibition: For determining the oviposition rate, 100 grains were taken randomly from each plastic container in each treatment. After seven days of treatments, grains were carefully examined under a magnifying glass (10X). Grains with eggs and

$$
\text { Mortality }\left(\%=\frac{\text { Total number of died pulse beetles }}{\text { Total number of released pulse beetles }} \times 100\right.
$$

\section{Data management and analysis}

The experiment was conducted in the laboratory by using a Completely Randomized Design (CRD). The data were analyzed with the help of the Analysis of Variance (two-way classifications). The data of the experiment was transformed (whenever necessary) by using suitable transformation value in order to make the analysis of variance valid and feasible.

\section{Result and Discussion \\ Oviposition inhibition}

The data presented in Table 1 on the number of oviposition of $C$. chinensis per 100 chickpea grain (Table 1) was found significant which were in the range of 30.00 to 32.67 eggs at the dose of $9 \mathrm{ml} \mathrm{kg}^{-1}$. At the dose of without eggs were separated and the total number of egg-bearing grains was recorded. After recording data on both grains with eggs and without eggs, returned to their respective plastic container and covered with a muslin cloth and tied with a rubber band and left undisturbed for further development.

Adult emergence (\%): Adult development performance was assessed by recording the number of $\mathrm{F} 1$ progeny that emerged from eggs. The emerged adults were counted and removed every day from the plastic container up to 7 consecutive days.

Adult mortality (\%): Data on adult mortality was recorded daily from the 1 st day to the 7 th day of pulse beetle emerged. After seven days, a total number of dead beetles were calculated and converted to a percentage by the following formula.

$6 \mathrm{ml} \mathrm{kg}{ }^{-1}$, coconut oil (31.33 eggs) and sesame oil (31.66 eggs) were found to be significantly different over the other three oils. At the dose of $3 \mathrm{ml} \mathrm{kg}^{-1}$, all oils did not differ significantly with the oviposited eggs range of 36.17 to 50.50 eggs. Whereas the total number of eggs on untreated control was 312.84 eggs.Present result is in partial conformity with the findings of Tabu et al. (2012) who reported that the effect of botanicals, inert materials and edible oils on oviposition of $C$. chinensis showed 5 to 30 eggs/100 seeds.

In the present study, it has been found that a total number of eggs laid on grains, obviously decrease as the rate of oil increases. A similar inference has been reached by Pandey et al. (1981); Das (1987) who reported 
that, if a higher dosage of oil is used for treatment, seeds could be protected from infestation for longer times. In general, these results suggested that it is possible to manage C. chinensis effectively by using the selected edible oils though there appeared a variation of efficacy due to concentration and exposure period.

\section{Adult mortality (\%)}

The data (Table 1) on the percentage in adult mortality of $C$. chinensis showed highest on coconut oil $(55.00 \%)$ at the dose of $9 \mathrm{ml} \mathrm{kg}^{-}$

${ }^{1}$ which differs significantly over the other oils at all doses. At the dose of 6 and $3 \mathrm{ml} \mathrm{kg}^{-1}$ none of the treatments were significant different, where the adult mortality percent range of 37.50 to $30.00 \%$ and 35.00 to $23.33 \%$ respectively. The present investigation was found to be in agreement of Bhardwaj and Verma (2012) who reported that maximum mortality of the pulse beetle in seeds coated with vegetable oils was with neem oil (72.22\%), followed by karanji $(65.56 \%)$, cedar $(53.33 \%)$, mustard $(38.44 \%)$ and olive $(32.89 \%)$, all oils differing significantly from one another except apricot $(29.56 \%)$.

\section{Adult Emergence (\%)}

The overall data on adult emergence inhibition percent of $C$. chinensis revealed that all oils differ significantly at the dose of $9 \mathrm{ml}$ $\mathrm{kg}^{-1}$, where adult emergence reduction percent were in the ranges of 96.49 to 94.98 . At the doe of $6 \mathrm{ml} \mathrm{kg}^{-1}$, the highest percentage in reducing adult emergence of $C$. chinensis per oviposited eggs in 100 chickpea grains was exhibited on sesame oil (96.67\%) followed by coconut oil (96.17\%) and mustard oil (95.04\%) which differ significantly over the other oils. The lowest percentage was found on groundnut oil (93.43\%) followed by olive oil $(93.91 \%)$ which did not differ significantly. At the dose of $3 \mathrm{ml} \mathrm{kg}^{-1}$, all oils did not differ significantly where adult emergence reduction percent were in the ranges of 92.83 to 87.06 . Nonetheless, they differ highly significantly from untreated control (29.25\%).

Similarly Khinchi et al. (2017) reported at $8 \mathrm{ml} \mathrm{kg}$-1 treatment inhibition was recorded as $85.57,70.22,66.27$, and 66.60 percent in the case of neem oil, groundnut oil, coconut oil, and sesamum oil, respectively. Likewise, in the lowest dose of $4 \mathrm{ml} \mathrm{kg}^{-1}$ of neem, groundnut, coconut, and sesamum oils the percent adult emergence inhibition obtained were 74.56, 63.34, 55.54, and 57.25, respectively. This result was in harmony to the finding by Khinchi et al. (2017) who revealed that higher doses of groundnut oil, coconut oil and sesamum oil at the highest dose of $12 \mathrm{ml}$ kg-1 grains resulted in adult emergence inhibition as 94.27, 78.57, 75.91 and 74.27 percent respectively. After a review of the data it could be concluded that coconut oil and sesame oil could be used as protectants of chickpea grains against $C$. chinensis infestation during storage. 
Journal of Agriculture and Ecology, 2020, Vol. 9, 41-47

http://saaer.org.in

Table 1. Effect of edible oils on development stages of $C$. chinensis

\begin{tabular}{|c|c|c|c|c|c|c|c|c|c|c|}
\hline \multirow{2}{*}{ Treatments } & \multirow{2}{*}{$\begin{array}{l}\text { Dose/ } \\
\mathrm{kg}\end{array}$} & \multicolumn{3}{|c|}{ Oviposition inhibition in number } & \multicolumn{3}{|c|}{ Adult mortality (\%) } & \multicolumn{3}{|c|}{ F1 C. chinensis emergence (\%) } \\
\hline & & 2018 & 2019 & Pooled & 2018 & 2019 & Pooled & 2018 & 2019 & Pooled \\
\hline & & 46.00 & 46.33 & 46.17 & 18.33 & 28.33 & 23.33 & 86.56 & 89.53 & 88.05 \\
\hline \multirow[t]{2}{*}{ Olive oil } & $3 \mathrm{ml}$ & $(6.82) \mathrm{a}$ & (6.84)a & $(6.83)$ & $(0.44) \mathrm{abc}$ & $(0.56) \mathrm{a}$ & $(0.50)$ & $(1.20) \mathrm{a}$ & (1.24)a & $(1.22)$ \\
\hline & & 40.00 & 38.67 & 39.34 & 40.00 & 45.00 & 42.50 & 93.11 & 94.71 & 93.91 \\
\hline \multirow[t]{2}{*}{ Olive oil } & $6 \mathrm{ml}$ & $(6.36) \mathrm{d}$ & $(6.26) \mathrm{b}$ & $(6.31)$ & (0.68)ef & $(0.74) \mathrm{c}$ & $(0.71)$ & $(1.31) \mathrm{c}$ & $(1.34) \mathrm{d}$ & $(1.33)$ \\
\hline & & 35.33 & 28.33 & 31.83 & 46.67 & 48.33 & 47.50 & 94.12 & 95.83 & 94.98 \\
\hline \multirow[t]{2}{*}{ Olive oil } & $9 \mathrm{ml}$ & $(5.98) \mathrm{f}$ & $(5.37) \mathrm{c}$ & $(5.68)$ & $(0.75) \mathrm{hi}$ & $(0.77) f g$ & $(0.76)$ & $(1.33) \mathrm{f}$ & $(1.37) \mathrm{e}$ & $(1.35)$ \\
\hline & & 34.67 & 39.67 & 37.17 & 35.00 & 35.00 & 35.00 & 91.72 & 93.94 & 92.83 \\
\hline \multirow[t]{2}{*}{ Coconut oil } & $3 \mathrm{ml}$ & $(5.92) \mathrm{b}$ & (6.34)a & (6.13) & $(0.63) \mathrm{d}$ & $(0.63) \mathrm{b}$ & $(0.63)$ & $(1.28) \mathrm{b}$ & $(1.32) b c$ & $(1.30)$ \\
\hline & & 31.33 & 31.33 & 31.33 & 43.33 & 43.33 & 43.33 & 96.44 & 95.89 & 96.17 \\
\hline \multirow[t]{2}{*}{ Coconut oil } & $6 \mathrm{ml}$ & $(5.64) \mathrm{e}$ & $(5.64) \mathrm{b}$ & $(5.64)$ & $(0.72) \mathrm{f}$ & $(0.72) \mathrm{c}$ & $(0.72)$ & (1.38)de & $(1.37) \mathrm{d}$ & $(1.38)$ \\
\hline & & 33.00 & 27.00 & 30.00 & 55.00 & 55.00 & 55.00 & 96.07 & 96.00 & 96.04 \\
\hline Coconut oil & $9 \mathrm{ml}$ & $(5.79) \mathrm{g}$ & $(5.24) \mathrm{c}$ & $(5.52)$ & $(0.84) \mathrm{k}$ & (0.84)hi & $(0.84)$ & $(1.37) \mathrm{f}$ & $(1.37) \mathrm{e}$ & $(1.37)$ \\
\hline Groundnut & & 54.33 & 46.67 & 50.50 & 15.00 & 25.00 & 20.00 & 85.47 & 88.65 & 87.06 \\
\hline oil & $3 \mathrm{ml}$ & $(7.40) \mathrm{c}$ & (6.87)a & (7.14) & $(0.40) \mathrm{a}$ & $(0.52) \mathrm{a}$ & $(0.46)$ & (1.18)a & (1.23)a & $(1.28)$ \\
\hline Groundnut & & 41.00 & 36.33 & 38.67 & 25.00 & 35.00 & 30.00 & 94.64 & 92.21 & 93.43 \\
\hline oil & $6 \mathrm{ml}$ & $(6.44) \mathrm{d}$ & $(6.07) \mathrm{b}$ & $(6.26)$ & $(0.52) \mathrm{g}$ & $(0.63) \mathrm{e}$ & $(0.58)$ & $(1.34) \mathrm{cd}$ & $(1.29) \mathrm{e}$ & $(1.32)$ \\
\hline Groundnut & & 36.00 & 29.33 & 32.67 & 35.00 & 43.33 & 39.17 & 96.13 & 95.94 & 96.04 \\
\hline \multirow[t]{2}{*}{ oil } & $9 \mathrm{ml}$ & $(6.04) f$ & $(5.46) \mathrm{c}$ & $(5.75)$ & $(0.63) \mathrm{j}$ & $(0.72) \mathrm{f}$ & $(0.68)$ & (1.38)f & $(1.37) \mathrm{e}$ & (1.38) \\
\hline & & 45.00 & 45.00 & 45.00 & 21.67 & 26.67 & 24.17 & 86.73 & 90.78 & 88.76 \\
\hline Mustard oil & $3 \mathrm{ml}$ & $(6.74) \mathrm{a}$ & (6.74)a & $(6.74)$ & $(0.48) b c$ & $(0.54) \mathrm{a}$ & $(0.51)$ & $(1.20) \mathrm{a}$ & $(1.26) \mathrm{ac}$ & $(1.23)$ \\
\hline
\end{tabular}


Journal of Agriculture and Ecology, 2020, Vol. 9, 41-47

http://saaer.org.in

\begin{tabular}{|c|c|c|c|c|c|c|c|c|c|c|}
\hline & & 38.33 & 39.33 & 38.83 & 36.67 & 36.67 & 36.67 & 95.37 & 94.71 & 95.04 \\
\hline \multirow[t]{2}{*}{ Mustard oil } & $6 \mathrm{ml}$ & $(6.22) \mathrm{d}$ & $(6.29) \mathrm{b}$ & $(6.26)$ & $(0.65) \mathrm{e}$ & $(0.65) \mathrm{de}$ & $(0.65)$ & (1.36)cde & $(1.34) \mathrm{d}$ & $(1.35)$ \\
\hline & & 32.00 & 28.67 & 30.34 & 45.00 & 51.67 & 48.34 & 96.34 & 95.83 & 96.09 \\
\hline \multirow[t]{2}{*}{ Mustard oil } & $9 \mathrm{ml}$ & $(5.70) \mathrm{h}$ & $(5.40) c$ & $(5.55)$ & $(0.74) \mathrm{h}$ & (0.80)ghi & $(0.77)$ & (1.38)f & (1.37)e & (1.38) \\
\hline & & 36.00 & 36.33 & 36.17 & 23.33 & 26.67 & 25.00 & 88.67 & 92.93 & 90.80 \\
\hline \multirow[t]{2}{*}{ Sesame oil } & $3 \mathrm{ml}$ & $(6.04) b$ & (6.07)a & $(6.06)$ & $(0.50) \mathrm{c}$ & $(0.54) \mathrm{a}$ & $(0.52)$ & $(1.23) \mathrm{ab}$ & $(1.30) \mathrm{c}$ & $(1.27)$ \\
\hline & & 31.67 & 31.33 & 31.50 & 35.00 & 40.00 & 37.50 & 97.34 & 96.00 & 96.67 \\
\hline \multirow[t]{2}{*}{ Sesame oil } & $6 \mathrm{ml}$ & $(5.67) \mathrm{e}$ & $(5.64) b$ & $(5.66)$ & $(0.63) \mathrm{e}$ & $(0.68) \mathrm{cd}$ & $(0.66)$ & (1.41)ed & $(1.37) \mathrm{d}$ & (1.39) \\
\hline & & 32.33 & 27.67 & 30.00 & 51.67 & 55.00 & 53.34 & 97.14 & 95.83 & 96.49 \\
\hline Sesame oil & $9 \mathrm{ml}$ & $(5.73) \mathrm{gh}$ & $(5.31) c$ & $(5.52)$ & (0.80)ik & $(0.84) \mathrm{i}$ & $(0.82)$ & $(1.40) \mathrm{g}$ & $(1.37) \mathrm{e}$ & (1.39) \\
\hline Untreated & & 320.67 & 305.00 & 312.84 & 5.00 & 5.00 & 5.00 & 40.03 & 18.47 & 29.25 \\
\hline Control & 0 & (17.91) & $(17.48)$ & $(17.70)$ & $(0.23)$ & $(0.23)$ & $(0.23)$ & $(0.68)$ & $(0.44)$ & $(0.56)$ \\
\hline S.Ed (土) & & 0.23 & 0.24 & 0.24 & 0.03 & 0.03 & 0.3 & 0.03 & 0.02 & 0.03 \\
\hline $\mathrm{CD}$ at $5 \%$ & & 0.47 & 0.49 & 0.48 & 0.06 & 0.06 & 0.06 & 0.06 & 0.04 & 0.05 \\
\hline
\end{tabular}

Data are mean of 3 replications

Figure in parentheses are square root (Oviposition) and angular transformed values

Means are separated by LSD test

Means having the same letters are non-significantly different at $5 \%$ level 


\section{Acknowledgements}

The author is thankful to Associate Prof. S.M. Haldhar, Department of Entomology, College of Agriculture, Central Agricultural University, Imphal for providing necessary facilities, moral support and follow-up throughout the investigation.

\section{References}

Ahmad F, Gaur PM \& Croser J. 2005. Chickpea (Cicer arietinum L.). Genetic resources, chromosome engineering and crop improvement-grain legumes, (1): 185-214.

Ahmad S, Haque A \& Mahmud H. 2003. Effect of pulse beetle, C. Chinensis L on oviposition and damage in some important genotypes of pulse crops in Bangladesh, Biomed. J., 2: 5.

Bhardwaj A \& Verma SC. 2012. Evaluation of vegetable oils against pulse beetle, Callosobruchus chinensis (Coleoptera: Bruchidae) infesting pea seeds (Pisum sativum L.). Pest Manag. Hort. Ecosys., 18(1): 46-53.

Choudhary SK, Deshwal HL \& Haldhar SM. 2017a. Intensity of losses due to Pulse beetle in Chick pea. Annals of Plant Protection Sciences 25 (2): 423-424.

Choudhary SK, Deshwal HL and Haldhar SM. 2017b. Investigate the host preference of
(Callosobruchus chinensis) in different stored Pulses. Annals of Plant Protection Sciences 25 (2): 419-421.

Das GP. 1987. Efficacy of neem oil on the egg grub mortality of Callosobruchus chinensis Linn. (Bruchidae: Coleoptera). Trop. Grain Leg. Bull., 34: 14-15.

Food and Agriculture Organization of the United Nations. 2016. http://www.fao.org/pulses- 2016/en/

Khinchi SK, Sharma MM, Khinchi MK, Bairwa DK, Acharya D Naga BL \& Naga RP. 2017. Studies on efficacy of certain vegetable oils against pulse beetle, Callosobruchus chinensis Linn. on chickpea, Cicer arietinum (L.) Int. J. Chemi. Stud., 5(3): 255-259.

Pandey GP, Doharey RB \& Varma BK. 1981. Efficacy of some vegetable oils for protecting greengram against the attack of Callosobruchus maculatus (Fabr.). Indian J. Agri. Sci., 51: 910-912.

Tabu D, Selvaraj T, Singh SK \& Mulugeta N. 2012. Management of Adzuki bean beetle (Callosobruchus chinensis L.) using some botanicals, inert materials and edible oils in stored chickpea. $J$. Agri. Techno., 8(3): 881-902. 